\title{
Allogeneic B7.1/HLA-A1 Transfected Tumor Cell Vaccine
}

National Cancer Institute

\section{Source}

National Cancer Institute. Allogeneic B7.1/HLA-A1 Transfected Tumor Cell Vaccine. NCI

Thesaurus. Code C70985.

An allogeneic whole cell vaccine, derived from irradiated allogenic tumor cells manipulated to express human B7.1 (CD80 antigen) and human leukocyte antigen (HLA) A1, with potential antitumor activity. Vaccination with allogeneic B7.1/HLA-A1 transfected tumor cell vaccine may elicit a cytotoxic $\mathrm{T}$ lymphocyte $(\mathrm{CT} \mathrm{L})$ response ag ainst similar host tumor cells, resulting in decreased tumor cell proliferation. 